\title{
Midwifery as a Future Career: Determinants of Motivation Among Prep Students in Harar, Eastern Ethiopia
}

This article was published in the following Dove Press journal: Advances in Medical Education and Practice

\author{
Daniel Tadesse $\mathbb{D}^{\prime}$ \\ Solomon Weldemariam (iD) ${ }^{2}$ \\ Hadgay Hagos ${ }^{2}$ \\ Alekaw Sema' \\ Meklit Girma ${ }^{2}$ \\ 'Midwifery Department, Dire Dawa \\ University, Dire Dawa, Ethiopia; \\ ${ }^{2}$ Midwifery Department, Mekelle \\ University, Mekelle, Tigray Regional State, \\ Ethiopia
}

Correspondence: Daniel Tadesse

Email daniel.tadesse@ddu.edu.et
Background: Midwifery is a profession that deals with care and advice during pregnancy, labor, childbirth and postpartum period including support for the newborn. Like other professions, the sustainability of midwives depends on recruiting new professionals who are inspired to train as their future career. In this regard, the inspiration of preparatory students to embracing the profession and secure the future midwife workforce is critical. In Ethiopia, there is no literature on the assessment of students' intention toward the midwifery profession. Hence, this study is crucial to fill data scarcity.

Objective: To assess the intention and related factors to choose midwifery as a future profession among preparatory students at Harar.

Methodology: An institutional cross-sectional study was conducted on preparatory students from March 20 to April 12/2019. Self-administered questionnaires were randomly given to 423 students. Multivariate logistic regression analysis was done for variables with p-value $<0.2$ in binary logistic regression. The odds ratio was used to measure the degree of association.

Results: Only $18.1 \%$ intended to choose midwifery as a future profession. The odds of considering to choose midwifery is 5 times higher in those who have a health professional mother $[\mathrm{AOR}=5.518 \mathrm{p}$-value 0.009]. Students who have good perceptions are 7 times more likely to choose the profession $[\mathrm{AOR}=7.072 \mathrm{p}$-value 0.00$]$. Students who perceived low regard toward the profession $[\mathrm{AOR}=0.231 \mathrm{p}$-value 0.001$]$ and blood contact as a barrier to be a midwife $[\mathrm{AOR}=0.174 \mathrm{p}$-value 0.001$]$ are less likely to choose it.

Conclusion: Preparatory students in Harar have minimal intention to choose midwifery. This is due to a lack of information about the profession, poor perception, low regard to the profession, and fear of blood contact. This finding contributes to the midwifery association and ministry of health to enhance positive perception toward the profession.

Keywords: intention, midwifery, profession, preparatory

\section{Background}

Midwifery is a health profession that is responsible and accountable to the partnership with women to give the necessary support, care, and advice during pregnancy, labor, and the postpartum period, and to provide care for the newborn and infant. ${ }^{1}$ The history of midwifery education has been counted for more than 65 years from the first post-basic training program at Gondar hospital in 1954 up to the current 31 public universities that provide a direct entry program. ${ }^{2,3}$ 
According to some international studies, the intention of high school students toward choosing the nursing profession as a future career was found to be less likely. For instance, from a survey conducted among high school students in Saudi Arabia, Bahrain, and Tanzania only $5.2 \%, 13.7 \%$ and $10 \%$ of them would consider nursing as a future career, respectively. ${ }^{4-6}$

Studies from different parts of the globe also identified factors preventing them from becoming a nurse such as perception toward the profession, perceived barriers to being a nurse such as long working hours and high workload were found to have a significant association. Parental occupation and parental educational level also influenced respondents' perceptions of nursing as a future career. ${ }^{4,5,7}$

Since midwives are the primary source of care for mothers and newborns at the most vulnerable time in their lives, a Shortage of midwives and high turnover are the major impediments to address the care. According to recent evidence, Ethiopia has an estimated number of 4725 midwives for a population of 85 million making a ratio of 1: 17,989 which is inconsistent with WHO recommendation of midwife population ratio (1:5000). Meeting the need for maternal and newborn health care in Ethiopia would require recruiting a lot more midwives. ${ }^{8}$

In Ethiopia students who achieved the lower qualifying score of entrance exam were assigned to the midwifery study program even though they may have not expressed any knowledge or interest in the program. This has contributed to a loss of respect for the profession, reduction of students' motivation, and professional quality. $^{11}$

This study is a significant input to show higher officials, Ethiopian midwives association, policymakers and related NGOs to revise the direction of their efforts toward recruiting interested and motivated professionals by adapting an approach that would increase the inspiration of younger ones thus ensuring the sustainability of the profession.

\section{Methods}

\section{Study Setting and Design}

An institution-based cross-sectional study was conducted in all of the five preparatory schools of Harar city (Aboker preparatory school, Aw-Abdal preparatory school, Betlhem preparatory school, SOS preparatory school and Hi-Tech preparatory school) from March 20/2019 to April 12/2019.

\section{Study Population and Sampling Procedure}

The study population includes all grade 12 students in Harar city. A single population proportion formula $[\mathrm{n}=$ $(\mathrm{z} \alpha / 2) 2 \mathrm{p}(1-\mathrm{p}) / \mathrm{d} 2$ ] was used to calculate the sample size with the assumption of $50 \%$ proportion of students' intention to choose midwifery profession, 95\% confidence level, $5 \%$ margin of error and $10 \%$ of non-response rate.

Overall, we recruited a total of 423 respondents. Two hundred and eighty students from Aboker preparatory school, 25 students from Aw-Abdal preparatory school, 43 students from Betelhem preparatory school, 41 students from SOS preparatory school and 34 students from HiTech preparatory school were allocated proportionally based on the number of students in each school.

Grade 12 enrollment was taken as inclusion criteria while enrollment in grade 11 was a criterion of exclusion since only grade 12 students are supposed to choose their future field of study (profession) after taking the entrance exam to higher education institutions.

\section{Data Collection Tool and Procedures}

A structured questionnaire was used after reviewing important literature on the problem under the study. ${ }^{5,9}$ It was translated into two local languages (Amharic and Oromiffa) then back to the English language.

The questionnaire was designed to obtain information on the main variables which is categorized under 4 section. A total number of 30 items were included in the data collection tool (9 socio-demographic, 3 awareness about midwifery profession, 13 perceptions toward midwifery profession statements, and 5 career choice-related questions). Perception-related questions were organized through statements with a Likert measurement scale while the rest of the questions includes "YES" or "NO" alternative and additional relevant alternative responses.

The data collectors were Five midwives who can speak local languages (Amharic and Oromiffa). A pre-test was conducted by taking $10 \%$ of the sample size (42 students) in Bisrate Gebriel preparatory school which is found outside of Harar which was under a similar setup. Appropriate modifications were made after analyzing the pretest result before the actual data collection. Data quality was assured by giving training and appropriate supervision for data collectors. The overall supervision was carried out by the principal investigator. The collected data were also crosschecked on a daily basis for its consistency and completeness. 


\section{Data Processing and Analysis}

The internal consistency of perception-related Likert scale questions was measured by Cronbach's alpha and it was reported 0.683 which is below the recommended value of Cronbach's alpha which is 0.70 . Meanwhile, the scale if item deleted was used to improve the reliability of the tool and an alpha value of 0.707 was reported when the first item is deleted. The collected data were entered into Epi Data version 4.2 and exported to SPSS version 20 for data processing and analysis. Descriptive statistics like percentage, mean, and standard deviation were done. Both bivariate and multivariable logistic regression analyses were computed to identify associated factors. The odds ratio along with $95 \%$ CI was computed to ascertain the association between independent and outcome variables. Variables that have a $p$-value of $<0.2$ at bivariate analysis were included in multivariable logistic regression to control possible confounding factors. Statistical tests at a p-value of $<0.05$ were considered as statistical significance.

The model fit was checked by the Hosmer and Lemeshow Test which is the most reliable test of model fit available in SPSS. Hence, the chi-square value for the Hosmer-Lemeshow Test is 10.478 with a significance level of 0.233 . This value is greater than 0.05 , therefore indicating the goodness of model fit.

\section{Results}

\section{Socio-Demographic Characteristics of Respondents}

Among 423 eligible sampled respondents, 417 students were responded to the questions yield a response rate of 98.5\%. The six non-responders were due to incomplete responses. As shown in Table 1, the age ranged from 17 to 22 with a mean age of 18.30 years $(\mathrm{SD}+0.88)$. (Table 1$)$

\section{Awareness and Perception Toward Midwifery Profession}

Four hundred and nine (98.1\%) have awareness about the midwifery profession. Among these, $78.2 \%$ have the awareness that midwifery study program has been provided at public universities.

On the perception dimension, $48.7 \%$ of respondents have a poor perception of the midwifery profession. As shown in Table 2, the lowest recorded score was for the statement "the pay in midwifery is reasonable" followed by "midwives' job is beyond delivering babies". While the highest score was for "midwives need knowledge and skill to provide a care" followed by midwifery is an important profession in the community (See Table 2).

\section{The Intention of Preparatory Students to} Choose Midwifery as a Future Profession From 409 grade 12 students who have the awareness about midwifery profession, only $18.1 \%$ (74) have the intention to go to midwifery study program while the rest $81.9 \%$ do not have this intention. Respondents differ in the reasons they gave to justify their intentions for considering midwifery as a future career. Accordingly, $8.8 \%$ said passion for caring (because it is a caring profession), 5.1\% said easy employability (to get job easily), 2.9\% said personal interest and the rest $1.2 \%$ said family recommendation.

On the other hand, accounting for lack of intention to consider this profession as a future career, the reasons include lack of interest in the field (49.4\%), fear of blood contact $(17.4 \%)$, stressful job (11.2\%), high workload (3.7\%), and insufficient information $(0.2 \%)$.

\section{Perceived Barriers to Be a Midwife}

As shown in Figure 1, there are seven perceived barriers to consider midwifery as a choice career. The majority of participants agree that these barriers to considering midwifery as a career are related to the fact that people have low regard for the profession. Others consider the midwife's nightshift work as a barrier for nightshift work neither interests nor motivates people to study midwifery (Figure 1).

\section{Influential Person to Choose Their Future Career}

As Figure 2 shows, the Majority of preparatory students put themself as influential people to decide their future careers while the minority claimed their friend as an influential person to choose their future career (see Figure 2).

\section{Factors Associated with the Intention of Preparatory Students Toward the Choice of Midwifery as a Future Profession}

As Table 3 shows, in bivariate analysis mothers' occupation, fathers educational level, mothers' educational level, having a healthcare professional friend/family member, source of information, perception toward the profession and from perceived barriers to becoming midwife, long working hour, people's low regard to the profession and 
Table I Socio-Demographic Characteristics for Intention to Choose Midwifery as a Future Profession and Related Factors Among Preparatory Students in Harar, Eastern Ethiopia, 2019

\begin{tabular}{|c|c|c|c|}
\hline \multirow[b]{2}{*}{ Variables } & $\begin{array}{l}\text { Demographic } \\
\text { Data }\end{array}$ & Frequency & Percentage \\
\hline & Categories & No. & $\%$ \\
\hline \multirow[t]{2}{*}{ Age } & 18 and below & 258 & 61.9 \\
\hline & 19 and above & 159 & 38.1 \\
\hline \multirow[t]{2}{*}{ Sex } & Male & 202 & 48.4 \\
\hline & Female & 215 & 51.6 \\
\hline \multirow[t]{4}{*}{$\begin{array}{l}\text { Father's } \\
\text { occupation }\end{array}$} & $\begin{array}{l}\text { Health } \\
\text { professional }\end{array}$ & 54 & 12.9 \\
\hline & Non-health & 351 & 84.2 \\
\hline & professional & & \\
\hline & Unemployed & 12 & 2.9 \\
\hline \multirow{4}{*}{$\begin{array}{l}\text { Mother's } \\
\text { occupation }\end{array}$} & Health & 37 & 8.9 \\
\hline & professional & & \\
\hline & Non-health & 298 & 71.5 \\
\hline & Unemployed & & 19.7 \\
\hline \multirow[t]{3}{*}{$\begin{array}{l}\text { Father's } \\
\text { educational level }\end{array}$} & $\begin{array}{l}\text { Primary and } \\
\text { below }\end{array}$ & 45 & 10.8 \\
\hline & Secondary & 135 & 32.4 \\
\hline & College/beyond & 237 & 56.8 \\
\hline \multirow[t]{3}{*}{$\begin{array}{l}\text { Mother's } \\
\text { educational level }\end{array}$} & $\begin{array}{l}\text { Primary and } \\
\text { below }\end{array}$ & & 21.8 \\
\hline & Secondary & 157 & 37.6 \\
\hline & College/beyond & 169 & 40.5 \\
\hline \multirow{2}{*}{$\begin{array}{l}\text { HCP relative or } \\
\text { friend }\end{array}$} & Yes & 255 & 61.2 \\
\hline & No & 162 & 38.8 \\
\hline \multirow{2}{*}{$\begin{array}{l}\text { Admitted/visiting } \\
\text { at hospital }\end{array}$} & Yes & 365 & 87.5 \\
\hline & No & 52 & 12.5 \\
\hline
\end{tabular}

fear of blood contact were found to be significantly associated factors with students' intention to consider midwifery profession as a future career.

In multivariable analysis mothers' occupation, perception toward midwifery profession, and perceived barriers to being a midwife such as people's lack of respect for the profession and blood contact were found to be significant factors that determine a students' intention of considering the midwifery profession as a future career.

Students who have health professional mothers are 5.51 times more likely to choose the profession than those who have unemployed mothers $[\mathrm{AOR}=5.51$
$(1.526,19.954) \mathrm{p}$-value 0.009]. Students who have good perception toward the profession are 7.07 more likely to choose the profession than those who have poor perception [AOR= $7.07(2.862,17.480)$, p-value 0.00]

The other significantly associated factor is the perceived barrier to becoming a midwife. Accordingly, people who have low regard for the profession are 0.23 less likely to choose the profession than those who do not have low regard. $[\mathrm{AOR}=0.23(0.099,0.536) \mathrm{p}$-value 0.001]. Again those who considered fear of blood contact as a barrier for becoming a midwife are 0.174 less likely to choose the profession than those who did not see this as a barrier [AOR $=0.17(0.060,0.500) \mathrm{p}$-value 0.001]. (see Table 3)

\section{Discussion}

Among the students assessed for their intentions to study midwifery as a future profession, only $18.1 \%$ of students responded to consider studying midwifery for a future career. This is a slightly higher figure compared to the study conducted on high school students in Riyadh, the capital of Saudi Arabia in which only 5.2\% of students indicated similar motivations toward the profession.

This difference could be attributed to one of the sociodemographic characteristics in which the influence of a close health professional (friend or family member) around students could determine their motivation. The Saudi study shows the majority of the respondents do not have a health professional friend or family member while in this study majority of the respondents have a health professional relative or friend. The Saudi study shows the majority of the respondents tend to be less exposed to or influenced by a health professional friend/ family member to produce inclination towards midwifery. On the other hand, in the present study, the higher tendency toward accepting the profession is because the majority of respondents have preexisting information about the profession through exposure to a health professional relative or friend. For the majority of students, preexisting information or orientation about the profession tend to produce a motive for being attracted to the profession. ${ }^{4}$

Similarly, the results in the present study are compared to a related study conducted in Nigeria. The study in Nigeria shows the magnitude of secondary school students who considered studying nursing as a future profession constitutes $46.25 \%$ which is much higher than the finding of the current study. This high figure is due to the positive attitudes Nigerian students' developed toward the nursing 
Table 2 Perception Toward Midwifery Profession for Intention to Choose Midwifery as a Future Profession and Related Factors in Harar, Eastern Ethiopia, 2019

\begin{tabular}{|c|c|c|c|c|c|}
\hline S. No. & Statements & $\begin{array}{l}\text { Agreed + } \\
\text { Strongly } \\
\text { Agreed }\end{array}$ & Neutral & $\begin{array}{l}\text { Disagreed + } \\
\text { Strongly } \\
\text { Disagreed }\end{array}$ & Mean \\
\hline I & Midwifery is a caring profession & $351(85.8)$ & $24(5.9)$ & $34(8.3)$ & 4.11 \\
\hline 2 & Midwifery is a respected profession & $154(37.7)$ & $36(8.8)$ & $219(53.6)$ & 2.92 \\
\hline 3 & Midwifery is a very important profession in the community & $397(97.1)$ & $9(2.2)$ & $3(0.7)$ & 4.44 \\
\hline 4 & Midwifery is not gender dependent profession/not only for females & $245(59.9)$ & $23(5.6)$ & $|4|(34.4)$ & 3.42 \\
\hline 5 & I think midwifery is a very interesting job & $97(23.7)$ & $103(25.20)$ & $209(5 \mathrm{l} .1)$ & 2.75 \\
\hline 6 & The pay in Midwifery is reasonable & $55(13.4)$ & $134(32.8)$ & $220(53.7)$ & 2.54 \\
\hline 7 & Midwives able to use their own initiative in their work & $140(34.2)$ & $74(18.1)$ & $195(47.7)$ & 2.89 \\
\hline 8 & Midwives works under lot of stress & $166(50.4)$ & $72(17.6)$ & $131(32.0)$ & 3.22 \\
\hline 9 & I can find a job in Midwifery wherever I go/it is easily employable & $130(31.8)$ & $98(24.0)$ & $181(44.3)$ & 2.64 \\
\hline 10 & Midwives job is beyond delivering babies/not only delivering babies & $108(26.4)$ & $31(7.6)$ & $271(66.0)$ & 2.88 \\
\hline 11 & Midwives need skill and knowledge to provide care & $393(96.1)$ & $5(1.2)$ & II (2.7) & 4.51 \\
\hline 12 & $\begin{array}{l}\text { Midwives are exposed to patients with dangerous diseases/ } \\
\text { infections at work place. }\end{array}$ & $105(25.7)$ & $102(24.9)$ & $202(49.4)$ & 2.74 \\
\hline \multirow[t]{2}{*}{13} & \multirow[t]{2}{*}{ Midwives job has a very contact with blood. } & $376(91.9)$ & $24(5.9)$ & $9(2.2)$ & 4.11 \\
\hline & & \multicolumn{2}{|l|}{ Mean $=3.32$} & \multicolumn{2}{|l|}{$\mathrm{SD}=0.44$} \\
\hline
\end{tabular}

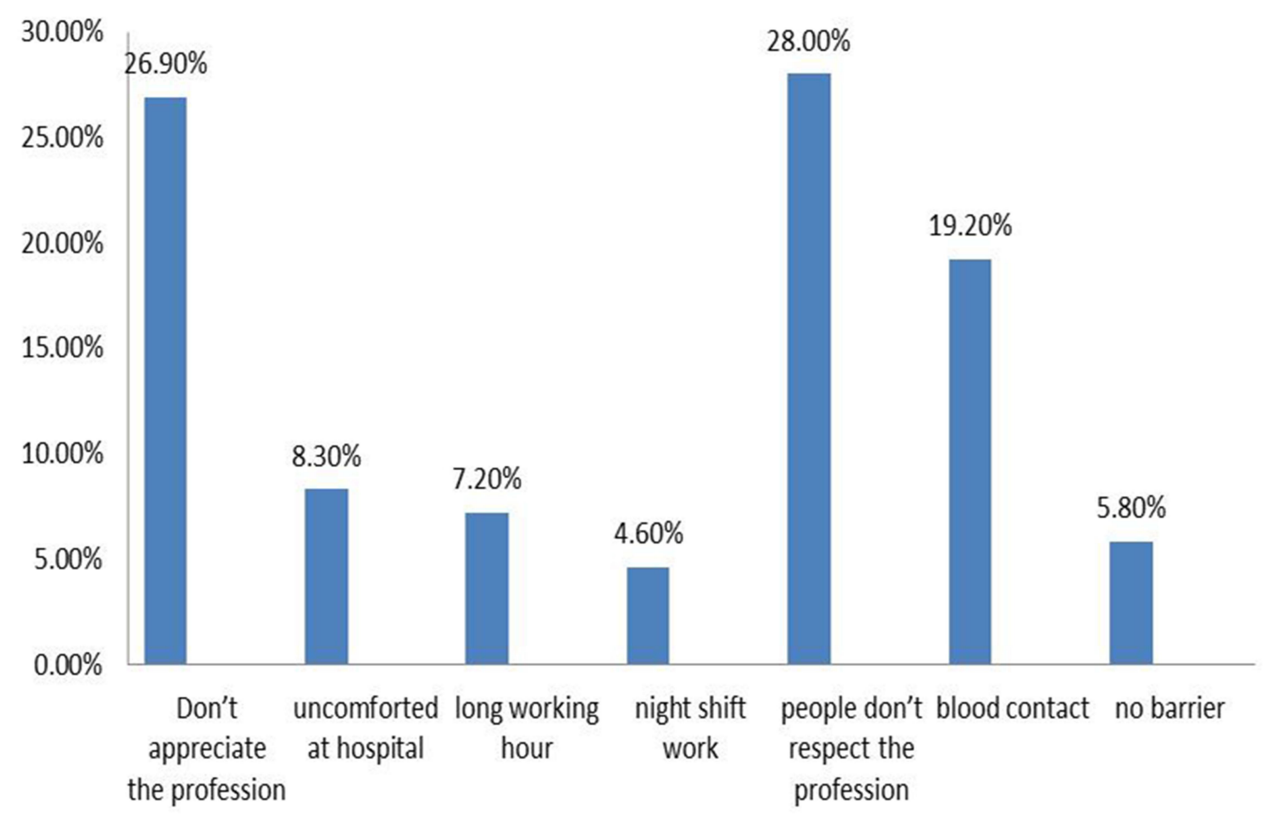

Figure I Participant's perceived barriers to be a midwife.

profession. For instance, in the current study, only 37.7\% of students agreed that midwifery is a respected profession and $13.4 \%$ accepted the pay in midwifery as reasonable. Whereas in the Nigerian study, the majority of respondents (91.25\%) accept the statement "nursing is a respected profession" and $78.7 \%$ agree that nursing pays a good salary. The positive perception of the profession has an influence and may attribute to the increasing number of students in Nigeria who consider nursing as a future career compared to the current study. ${ }^{9}$

In this study, mothers' occupation has also been significantly associated with preparatory students' intention 


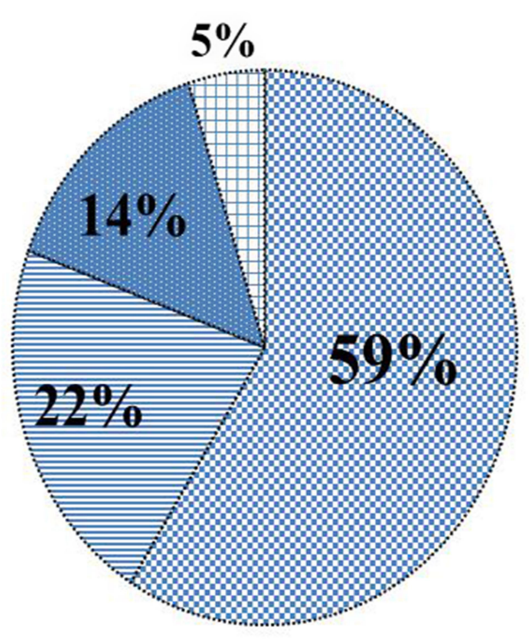

\section{My self}

黨 My teacher

My parents

Friends

Figure 2 Participant's influential persons to choose their future career.

to study midwifery as a future career. Students who have health professional mothers more likely to tend to consider midwifery as a profession than those who have non-health professional mothers. This finding concurs with the result of a study conducted on high school students in Bahrain which also revealed parental occupation as having a significant positive influence on students' perception toward a nursing profession as a future career. That is, students with a healthcare professional mother tend to develop a better perception toward the nursing profession which in turn will increase the likelihood to consider the profession as a future career. ${ }^{5}$

According to the finding of the present study, the other indicator that shows a significant association with students' choice to do midwifery is their perception of the

Table 3 Bivariate and Multivariate Analysis Result for the Intention to Choose Midwifery as a Future Profession and Related Factors Among Preparatory Students in Harar, Eastern Ethiopia, 2019

\begin{tabular}{|c|c|c|c|c|c|}
\hline Variables & Category & Have Intention & No Intention & COR $[95 \% \mathrm{Cl}]$ & AOR $[95 \% \mathrm{Cl}]$ \\
\hline \multirow[t]{3}{*}{ Mothers' occupation } & Health $* *$ & 20 & 17 & $2.916(1.300,6.539)$ & $5.518(1.526,19.954)$ \\
\hline & Non health * & 31 & 261 & $0.294(0.160,0.542)$ & $0.510(0.231,1.126)$ \\
\hline & Unemployed & 23 & 57 & 1 & 1 \\
\hline \multirow[t]{3}{*}{ Father educational level } & Primary \& below * & 14 & 29 & 3.130 (I.49I, 6.57I) & $2.435(0.797,7.437)$ \\
\hline & Secondary* & 29 & 105 & $1.791(1.024,3.131)$ & $1.522(0.716,3.235)$ \\
\hline & College/beyond & 31 & 201 & 1 & 1 \\
\hline \multirow[t]{3}{*}{ Mother educational level } & Primary \& below * & 31 & 57 & $2.800(1.535,5.107)$ & $3.304(1.082,10.092)$ \\
\hline & Secondary & 16 & 139 & $0.593(0.306,1.148)$ & $1.029(0.379,2.792)$ \\
\hline & College/beyond & 27 & 139 & 1 & 1 \\
\hline \multirow[t]{2}{*}{ Having HCP friend/family member } & Yes * & 58 & 196 & $2.571(1.419,4.659)$ & $\mathrm{I} .046(0.464,2.36 \mathrm{I})$ \\
\hline & No & 16 & 139 & 1 & 1 \\
\hline \multirow[t]{3}{*}{ Source of information } & Media & 22 & $15 \mid$ & $\mathrm{I} .093(0.46 \mathrm{I}, 2.589)$ & $0.715(0.236,2.167)$ \\
\hline & School teacher & 5 & 35 & I.07I $(0.325,3.53 I)$ & I.238 $(0.293,5.227)$ \\
\hline & Midwife * & 39 & 89 & $3.287(1.436,7.523)$ & $0.970(0.306,3.077)$ \\
\hline Been in hospital & 8 & 60 & 1 & 1 & \\
\hline \multirow[t]{2}{*}{ Perception for midwifery profession } & Poor & 8 & 191 & 1 & 1 \\
\hline & Good ** & 66 & 144 & $10.943(5.092,23.515)$ & $7.072(2.862,17.480)$ \\
\hline \multirow[t]{2}{*}{ Long working hour } & No & 62 & 316 & 1 & I \\
\hline & Yes * & 12 & 19 & $3.219(1.487,6.968)$ & I.I54 (0.436, 3.056) \\
\hline \multirow{2}{*}{$\begin{array}{l}\text { People do not respect the } \\
\text { profession }\end{array}$} & No & 64 & 224 & 1 & I \\
\hline & Yes $* *$ & 10 & 111 & $0.315(0.156,0.638)$ & 0.23 I $(0.099,0.536)$ \\
\hline \multirow[t]{2}{*}{ Contact with blood } & No & 69 & 257 & 1 & I \\
\hline & Yes $* *$ & 5 & 78 & $0.239(0.093,0.613)$ & $0.174(0.060,0.500)$ \\
\hline
\end{tabular}

Notes: *Show statistically significant association in bivariate logistic regression. **And bold numbers: Show statistically significant association in multivariate logistic regression. 
profession. The more positive perception they have about the profession, the more likely they are attracted to it. This finding is in line with the studies conducted among high school students' intention toward the nursing profession in Bahrain and Saudi Arabia. Both studies show that good perception toward the profession increases the likelihood to choose it. ${ }^{4,5}$

This study also shows factors that significantly determine the students' motivation to consider midwifery as a future career. It identifies low regard for the profession and dislike or fear of contact with blood as barriers to becoming a midwife.

That is, when students are convinced to have low regard and appreciation for midwifery and become phobic for contact with blood, the profession tends to suffer from less number of interested students who choose midwifery as a future career. This perceived barrier in the current study however is inconsistent with the study conducted in India. In the latter study, long working hours and the high workload of a midwife are perceived to have a significant negative influence on students' intention and motivation toward nursing as a future career. According to the study in India, nurses work from 9 to 14 hours a day, and this is a bit longer than the trend in the context of Ethiopia. So the long working hours of nurses tend to demotivate or discourage students from taking nursing as their future career. $^{7,10}$

\section{Conclusion and Recommendation}

This study has shown that preparatory students in Harar have minimal intention to choose midwifery as a future profession. This is because of demotivation or lack of interest owing mainly to four determinant factors such as lack of prior information or orientation about the profession, poor perception, low regard to the profession, and dislike or fear of blood contact.

The presence of a health professional in the household (a mother, for instance) tends to increase the likelihood of a student to choose midwifery as a future profession. This will help the student develop prior information, orientation and motivation to the profession. On the contrary, fixing poor perception and low regard toward the profession, on one hand, and a perceived fear or dislike of blood contact, on the other hand, result in a detrimental effect toward the student's intention to choosing midwifery as a future career.

Hence, the Ministry of education should do promotion and orientation work by providing detailed information about midwifery. One way of achieving this is by assigning career choice counselors at preparatory school levels. Promotional works through mass media play a crucial role in enhancing positive views of the profession. Marketing midwifery as a profession has an important role among preparatory students. This is significant in addressing and changing the common misconceptions like "midwives' job is only delivering babies" and enhancing the positive image in the community.

Besides, an in-depth qualitative study should be undertaken to explore the attitude of preparatory students toward the midwifery profession.

\section{Abbreviation}

AOR, adjusted odds ratio; COR, crudes odds ratio; HCP, healthcare professional; NGO, non-governmental organization; SD, standard deviation; WHO, World Health Organization.

\section{Data Sharing Statement}

All the data of this study are available from the corresponding author upon request.

\section{Ethical Consideration}

Ethical clearance was obtained from the institutional ethical review board of Mekelle University, College of Health Sciences. An official letter of permission was written to the Harari regional bureau of education. Participants were informed about the purpose, benefit, risk, confidentiality of the information, and the voluntary nature of participation in the study. Data were collected after informed written consent was obtained from each participant that their data will be included in publications. Participants under the age of 18 years were approved by the ethics committee to provide informed consent by their respective school directors on behalf of students.

\section{Acknowledgment}

We are very grateful to Mekelle University for financially to this study and the Department of Midwifery for its mentorship. We also thank all study participants for their time and willingness in responding to our questionnaire. Last but not least, our deepest gratitude goes to $\mathrm{Mr}$. Beniam Mitiku (Phd) for his grate input for the language improvment. 


\section{Author Contributions}

All authors made a significant contribution to the work reported, whether that is in the conception, study design, execution, acquisition of data, analysis, and interpretation, or in all these areas; took part in drafting, revising, or critically reviewing the article; gave final approval of the version to be published; have agreed on the journal to which the article has been submitted and agree to be accountable for all aspects of the work.

\section{Funding}

The data collection process for this work has been funded by Mekelle University. The study was originally conducted as partial fulfillment for the requirements of the degree of MSc in Midwifery at Mekelle University, College of Health Sciences, Department of Midwifery. Hence, the institution was involved in the project through monitoring and evaluation of the work from the beginning to the result submission. But this organization did not involve in designing, analyzing, critical review of its intellectual content, preparation of the manuscript and the budget funded by this organization did not include for publication.

\section{Disclosure}

The authors declare that they have no conflicts of interest.

\section{References}

1. Confederation I, Icm TEssential competencies for basic midwifery practice. International confederation of midwives. 2013.

2. UNFPA. Investing in Midwives. Stories from Ethiopia. 2014:3

3. Universities Intake Capacity for 2011 Ethiopia. Academic Year Entry. Ethiopia Education. 2011.

4. Al-Omar BA. knowledge, attitudes, and intention among Saudi high school students towards the nursing profession in Riyadh city, Saudi Arabia. Saudi Med J. 2004;25:153.

5. Tawash EA. Factors Influencing The High School Students 'Choice of a Nursing Career in Bahrain: Development of a Best Practice Model for Nursing Recruitment. Dublin: Royal College of Surgeons in Ireland. 2016.

6. Achilles K. Image of nursing profession as viewed by secondary school students in Ilala District, Dar es Salaam. DMSJ. 2010;17 (1): $12-18$

7. Shiroor G, Lily PMM. Knowledge and attitude regarding nursing as a Career among adolescence. Int J Multidiscip Res Dev. 2017. 4 (8):90-91.

8. Communications SG. New Life and New Hope - training Midwives in Ethiopia.Sandoz International GmbH . 2017;3(p).

9. OO A, AJ A, Adedoyin O. Adolescents ' perception of career choice of nursing among selected secondary schools in Jos, Nigeria. International journal of nursing and midwifery. 2015;7 (February):21-29.

10. Why nurses go unheard in India - even when they strike. Available from: Https://scroll.in/pulse/815812/why-nurses-go-unheard-in-India-evenwhen-they-strike. Accessed December 24, 2020. June 19, 12:41 AM.

11. Fullerton JT, International F, Johnson PG, Vivio D, International F. Quality considerations in midwifery pre-service education. Elsevier. 2011;27(3):310.
Advances in Medical Education and Practice

\section{Publish your work in this journal}

Advances in Medical Education and Practice is an international, peerreviewed, open access journal that aims to present and publish research on Medical Education covering medical, dental, nursing and allied health care professional education. The journal covers undergraduate education, postgraduate training and continuing medical education

\section{Dovepress}

including emerging trends and innovative models linking education, research, and health care services. The manuscript management system is completely online and includes a very quick and fair peer-review system. Visit http://www.dovepress.com/testimonials.php to read real quotes from published authors. 